\title{
Erratum to: Breast cancer risk models: a comprehensive overview of existing models, validation, and clinical applications
}

\author{
Jessica A. Cintolo-Gonzalez ${ }^{1}$ - Danielle Braun ${ }^{2,3}$ - Amanda L. Blackford ${ }^{4}$. \\ Emanuele Mazzola $^{3}$ - Ahmet Acar ${ }^{1} \cdot$ Jennifer K. Plichta ${ }^{5} \cdot$ Molly Griffin $^{1}$. \\ Kevin S. Hughes ${ }^{1}$
}

Published online: 21 June 2017

(C) Springer Science+Business Media, LLC 2017

\section{Erratum to: Breast Cancer Res Treat DOI 10.1007/s10549-017-4247-z}

In the paragraphing describing the Tice model, while we do acknowledge that this model was validated in an external cohort from the Mayo Mammography Health Study, an erroneous statement remains in the following paragraph stating "This model has yet to be validated outside its original study population." As described in the preceding paragraph, this model was validated outside its original study population. Additionally, the creators of the Tice model prefer it to be labeled as the "Breast Cancer Surveillance Consortium (BCSC) model (AKA: Tice model)" rather than label it as Tice model (AKA: Breast Cancer Surveillance Consortium (BCSC) model) given that $\mathrm{BCSC}$ is how the model is labeled for the online tool and iphone application.

The online version of the original article can be found under doi:10.1007/s10549-017-4247-z.

Jessica A. Cintolo-Gonzalez

jcintolo-gonzalez@partners.org

1 Division of Surgical Oncology, Massachusetts General Hospital, Boston, MA, USA

2 Department of Biostatistics, Harvard University T H Chan School of Public Health, Boston, MA, USA

3 Department of Biostatistics and Computational Biology, Dana-Farber Cancer Institute, Boston, MA, USA

4 Department of Oncology, Johns Hopkins University School of Medicine, Baltimore, MD, USA

5 Duke University Health Systems, Durham, NC, USA 